\title{
Clinical and biochemical findings in ten patients with benign myalgic encephalomyelitis
}

\author{
A. M. RAMSAY \\ M.A., M.D. \\ A. RUNDLE \\ D.Sc., M.R.C.Path.
}

Infectious Diseases Department, Royal Free Hospital, London, and St Lawrence's Hospital, Caterham

\begin{abstract}
Summary
Ten patients in whom the clinical findings were consistent with the syndrome variously described as 'benign myalgic encephalomyelitis', 'epidemic neuromyasthenia', 'Royal Free disease' and 'Icelandic disease' were investigated for blood levels of myoglobin and various enzymes. Although there is no clinical resemblance between the two diseases, the biochemical pattern bears a close similarity to that found in Duchenne muscular dystrophy (DMD) though differing sharply in that no rise in creatinine kinase levels was found. These findings are discussed with particular reference to recent suggestions that the permeability of cell membranes may be impaired by changes in intracellular energy mechanisms.
\end{abstract}

\section{Clinical features}

In 9 of the cases the illness followed an upper respiratory infection but in case 3 it was preceded by a severe gastro-intestinal infection.

The dominant clinical features could be classified as:

(1) Abnormal muscular fatigability and weakness. Muscular power was restored by a period of rest but recurred following further activity. Severe pain, particularly in the legs and back, was sometimes accompanied by involuntary spasm or twitching of muscles. Paraesthesiae and a sensation of numbness in the lower limbs were commonly experienced.

(2) Circulatory impairment was a feature of all cases, coldness of the extremities and acute sensitivity to alterations in temperature being a general complaint. In case 4 there were periods of hypothermia with violent attacks of shivering and profuse sweating suggestive of hypothalamic damage.

(3) Impairment of memory and inability to concentrate was common to all patients. Some experienced periods of confusion and profound depression.

Of the 10 cases, 8 were female and 2 male. The age at onset varied from 22 to 51 years. The duration of illness in the 10 cases was $35,9,6,3,2,23,17,2,5$, and 17 years respectively. A tendency to severe relapses was a feature of cases $6,7,9$ and 10 . Only case 6 developed the illness in the course of an epidemic; the remainder were all sporadic cases thus providing an important indication of the endemicity of the disease.

\section{Biochemical findings \\ Methods}

Serum levels of creatinine kinase (EC 2.7.3.2) aspartate aminotransferase (EC 2.6.1.1) and alanine aminotransferase (EC 3.4.1.1) were estimated at 340 $\mathrm{nm}$ using commercial kits (Boehringer, Mannheim). Glutamyl transferase was estimated at $405 \mathrm{~nm}$ with L- $\gamma$-glutamyl-p-nitranilide as substrate (Boehringer Whole blood lactate, pyruvate and ATP were est $B$ mated after precipitation in ice-cold perchlorate $\frac{\mathbb{Q}}{\overrightarrow{0}}$ $340 \mathrm{~nm}$ (Boehringer). Serum myoglobin was est mated by radio-immune assay (Eurotype Service Ltd, London). All colorimetry was carried out on a Pye-Unicam SP 1700 recording spectrophotometer. Table 1 shows that all GOT enzyme levels were abnormal with gross elevations in cases 1 and 7. The GPT enzyme was only raised in cases 6 and 7 and an element of chronic cholecystitis was known to be present in the latter. The creatinine kinase levels were normal in all cases. The abnormal level of $\gamma$-glutamyl transferase in case 8 could have resulted from concomitant hepatitis.

Table 2 shows fasting whole blood levels of lactic acid, pyruvic acid and ATP in 5 cases. Three of these, cases 2, 3 and 5, had elevated myoglobin levels. Case 1 was not tested. The ATP level was normal in all 5 cases. The serum pyruvic acid was significantly reduced in all 5 but the lactic acid was low in only 1 case. The gross elevation of lactic acid in case 2 corresponds with the abnormal $\gamma$-glutamyl transferase level shown in Table 1.

\section{Discussion}

The varying patterns of the enzymes GOT and GPT are similar to those found in muscular dystrophy. For instance, Schmidt and Schmidt (1967) collected statistics showing elevated levels of GOT $(60 \%)$, and GPT $(78 \%)$ in progressive muscular dystrophy. Adornato, Kagen and King Engel (1978) observed 
TABLE 1. Serum myoglobin (in $\mu \mathrm{g} / \mathrm{ml}$ ) and various serum enzyme levels (all in i.u./l) in 10 cases of benign myalgic encephalomyelitis

\begin{tabular}{|c|c|c|c|c|c|c|c|}
\hline Case No. & Sex & $\begin{array}{c}\text { Myog } \\
1 \text { st }\end{array}$ & $\begin{array}{l}\text { lobin } \\
\text { 2nd }\end{array}$ & CPK & $\gamma$-GTP & GOT & GPT \\
\hline $\begin{array}{r}1 . \\
2 . \\
3 . \\
4 . \\
5 . \\
6 . \\
7 . \\
8 . \\
9 . \\
10 .\end{array}$ & $\begin{array}{l}\mathbf{F} \\
\mathbf{F} \\
\mathbf{F} \\
\mathbf{M} \\
\mathbf{F} \\
\mathbf{F} \\
\mathbf{F} \\
\mathbf{M} \\
\mathbf{F} \\
\mathbf{F}\end{array}$ & $\begin{array}{r}48 \\
62 \\
125 \\
175 \\
280 \\
240 \\
330 \\
140 \\
840 \\
175\end{array}$ & $\begin{array}{c}38 \\
44 \\
106 \\
125 \\
185^{*} \\
112^{*} \\
370 \\
235 \\
70^{*} \\
134\end{array}$ & $\begin{array}{l}12 \\
12 \\
17 \\
12 \\
17 \\
17 \\
37 \\
37 \\
25 \\
25\end{array}$ & $\begin{array}{r}23 \\
11 \\
15 \\
21 \\
13 \\
8 \\
31 \\
508 \\
13 \\
16\end{array}$ & $\begin{array}{r}80 \\
40 \\
36 \\
37 \\
37 \\
20 \\
224 \\
31 \\
21 \\
24\end{array}$ & $\begin{array}{r}14 \\
7 \\
11 \\
8 \\
6 \\
42 \\
56 \\
10 \\
12 \\
18\end{array}$ \\
\hline Normal values & $\begin{array}{l}\mathbf{F} \\
\mathbf{M}\end{array}$ & \multicolumn{2}{|c|}{$\begin{array}{l}12-76 \\
19-96\end{array}$} & $0-50$ & $\begin{array}{l}4-18 \\
6-28\end{array}$ & $0-12$ & $0-12$ \\
\hline
\end{tabular}

*Subjects in a recovery phase when second blood sample taken.

CPK, creatinine kinase; $\gamma$-GTP, gamma glutamyl peptidase; GOT, aspartate aminotransaminase; GPT, alanine aminotransaminase.

TABLE 2. Fasting whole blood levels of pyruvate, lactate and ATP (all in $\mathrm{mg} / 100 \mathrm{ml}$ ) in 5 cases of benign myalgic encephalomyelitis

\begin{tabular}{ccrrc}
\hline Case No. & Sex & Pyruvate & Lactate & \multicolumn{1}{c}{ ATP } \\
\hline 1. & M & 0.13 & $7 \cdot 8$ & 24.2 \\
2. & M & 0.24 & $49 \cdot 3$ & 13.7 \\
3. & F & 0.09 & 12.8 & 21.8 \\
4. & F & 0.09 & 11.8 & 18.4 \\
5. & F & 0.19 & 11.6 & 22.1 \\
Normal values & $0.36-0.59$ & $9-16$ & $19-32$ \\
\hline
\end{tabular}

myoglobinaemia in 14 of 18 patients studied; similar elevations were found in 10 of 16 known carriers of Duchenne muscular dystrophy (DMD). More recently Hansen, Lademann and NørgaardPedersen (1978) using the much more sensitive radio-immune assay procedure confirmed this finding in 7 of 8 patients with DMD and in 2 known carriers of the disease. Since so much of the biochemistry in these 10 cases resembles that found in progressive muscular dystrophy it is not easy to account for the sharp divergence in respect of the creatinine kinase levels. A difference in the molecular weight of creatinine kinase and myoglobin might afford an explanation. Whereas creatinine kinase is a relatively large molecule with a mol. wt of 81000 , myoglobin has a mol. wt of only 17500 .
In a recent survey of clinical enzymology Wilkinson (1978) discusses the release of enzymes from cells. He concludes that intracellular energy content is important in the control of membrane permeability and instances loss of enzymes resulting from a variety of insults such as anoxia, deprivation of glucose, high potassium concentrations, high energy phosphates and metabolic inhibitors to both rat muscle and human erythrocytes. If the aetiological factor in benign myalgic encephalomyelitis impairs the permeability of the muscle cell membrane as a result of changes in the intracellular energy content this could be followed by a differential loss of intracellular proteins.

\section{References}

Adornato, B.T., Kagen, L.J. \& King Engel, W. (1978) Myoglobinaemia in Duchenne muscular dystrophy patients and carriers. A new adjunct to carrier detection. (Correspondence) Lancet, ii, 499.

Hansen, K.N., Lademan, A. \& NørgaArd-Pedersen, B. (1978) Potential of radioimmunoassay of myoglobin in amniotic fluid and serum in prenatal diagnosis of Duchenne muscular dystrophy. (Correspondence) Lancet, ii, 1250.

Schmid, E. \& Schmidt, F.W. (1967) Guide to Practical Enzyme Diagnosis. Boehringer \& Sohn, Mannheim.

Wilkinson, J.H. (1978) Clinical neurology. Journal of the Royal Society of Medicine, 71, 241. 